\title{
Dendrimer modified SWCNTs for High Efficient Delivery and Intracellular Imaging of survivin siRNA
}

Can Wang ${ }^{1}$, Zhiming $\mathrm{Li}^{2}$, Bing Liu ${ }^{2}$, Quande Liao ${ }^{1 *}$, Chenchen $\mathrm{Bao}^{2}$, Hualin $\mathrm{Fu}^{2}$, Bifeng Pan ${ }^{2}$, Weilin Jin², Daxiang Cui ${ }^{2 *}$

${ }^{1}$ Xiangya Hospital of Central South University, 87 Xiangya Road, Changsha410008, Hunan, P. R. China

${ }^{2}$ Institute of Nano Biomedicine and Engineering, Key Laboratory for Thin Film and Microfabrication Technology of the Ministry of Education, Research Institute of Micro/Nano Science and Technology, Key Laboratory for the Genetics of Developmental \& Neuropsychiatric Disorders of Ministry of Education, Bio-X Center, Shanghai JiaoTong University, Dongchuan Road 800, 200240 Shanghai, P. R. China

* Corresponding author: Quande Liao (qiandeliao@yahoo.cn), Daxiang Cui (dxcui@sjtu.edu.cn)

\begin{abstract}
Herein we reported that polyamidoamine dendrimer (PAMAM) modified single walled carbon nanotubes (PSWCNTs) were successfully used for high efficient delivery and intracellular imaging of survivin siRNA vector. No.4 generation of PAMAM dendrimers were used to modify single walled carbon nanotubes, and characterized by high resolution transmission electron microscopy (HR-TEM), and atom force microscopy (AFM), survivin shRNA vectors were constructed and identified, and then dendrimer-modified SWCNTs were mixed with survivin shRNA vectors, resultant dendrimer-SWCNTs-survivin shRNA vector mixtures co-cultured with human gastric cancer MGC803 cells, then the expression of survivin shRNA vectors in MGC803 cells was observed by fluorescent microscopy, cell viability was analyzed by MTT method. Results showed that survivin shRNA vector was successfully expressed in MGC803 cells, and MGC 803 cell growth was markedly inhibited. In conclusion, dendrimer (PAMAM) modified single walled carbon nanotubes can be used for high efficient delivery and intracellular imaging of siRNA, and own great potential in applications such as gene or drug delivery and tumor targeted imaging and simultaneous therapy in near future.
\end{abstract}

Keywords: Polyamidoamine dendrimer; Single walled carbon nanotube; Delivery system; siRNA; Imaging

Citation: C. Wang et al. Dendrimer modified SWCNTs for High Efficient Delivery and Intracellular Imaging of survivin siRNA. Nano Biomed. Eng. 2013, 5(3), 131-136. DOI: $10.5101 /$ nbe.v5i3.p131-136.

\section{Introduction}

Carbon nanotubes, as a class of stiff, stable and hollow nanomaterials with many unique properties such as mechanical, physical and chemical properties, have been being explored application in biomedical engineering and medical chemistry [1-3]. For example, carbon nanotubes have been used as delivery system for gene therapy [4], also used for biosensor for ultrasensitive detection of biomarkers [5], more important, carbon nanotubes can be used for near infrared imaging and photothermal therapy [6]. In our previous work, we also confirmed that carbon nanotubes can be filled with DNA or peptide molecules $[7,8]$, can take antisense oligonucleotides into HL-60 cells and inhibited tumor cell growth [9], highly suggesting that carbon nanotubes may be good delivery system and have highly potential in gene or drug storage and delivery system in molecular therapy of diseases.

Up to date, many data showed that carbon nanotubes own cytotoxicity, and single walled carbon nanotubes exhibited stronger toxicity than multi-walled carbon nanotubes (MWCNTs) [10-12]. How to decrease carbon nanotubes' toxicity and enhance carbon nanotubes biocompatibility have become scientists' concerns, many methods have been tried [13]. So far, CNTs' toxicity may arise from resident metal nanoparticles, and induced ROS reaction, therefore, CNTs' surface functionalization becomes the key step to enhance CNTs' biocompatibility $[14,15]$. Our data showed that single walled carbon nanotubes exhibit dual-phase regulation to exposed cells, which is highly depending on SWCNTs' amount and surface properties. Some studies show that CNTs can be kicked out of mice or other animal bodies by kidney or liver-gall intestinal tracts [16]. Therefore, CNTs exhibited limited toxicity in vivo, and still may own potential applications in human body under the reasonable dose control.

In our previous work, we established the method of dendrimer grown on the surface of carbon nanotubes [17], we also used dendrimer modified MWCNTs to realize gene high efficient delivery for tumor therapy or stem cell growth regulation [18-20]. However, few reports is 
As shown in Scheme 1, pristine SWCNTs were added to $\mathrm{H}_{2} \mathrm{SO}_{4} / \mathrm{HNO}_{3}(\mathrm{v} / \mathrm{v}=3: 1)$. The mixture was placed in an ultrasonic bath for $60 \mathrm{~min}$ and then stirred for $24 \mathrm{~h}$ while being boiled under reflux. The mixture was then vacuumfiltered through a $0.22 \mu \mathrm{m}$ Millipore polycarbonate membrane and subsequently washed with distilled water until the $\mathrm{pH}$ of the filtrate was ca. 7, yielding $\mathrm{COOH}$ CNTs $0.2 \mathrm{~g}$ amine terminated PAMAM dendrimer were added to the solution. The solution was placed in an ultrasonic bath for $60 \mathrm{~min}$ and the mixture was stirred for $24 \mathrm{~h}$ at $50^{\circ} \mathrm{C}$. The mixture was subsequently filtered and washed three times with water. The product was dispersed in water to give a SWCNT-PAMAM dendrimer aqueous solution.

\subsection{Characterization of dendrimer-modified SWCNTS by HR-TEM}

The average particle size, size distribution and morphology of SWCNTs and dendrimer coated SWCNTs were examined using a high resolution transmission electron microscope $((\mathrm{Hitachi} \mathrm{H}-700 \mathrm{H})$ at a voltage of $80 \mathrm{kV}$. The aqueous dispersion of the particles was drop-cast onto a carbon coated copper grid and the grid was air dried at room temperature before viewing under the microscopy.

\subsection{In vitro cell viability evaluation of dendrimer- modified SWCNTs by MTT}

To determine cell viability, the MGC803 cells were plated at a density of $1 \times 10^{4}$ cells/well in 96 well plate at $37^{\circ} \mathrm{C}$ in $5 \% \mathrm{CO}_{2}$ atmosphere. After $24 \mathrm{~h}$ of culture, the medium in the wells was replaced with the fresh medium containing dendrimer coated SWCNTs in concentration range $0-2.0 \mathrm{mg} / \mathrm{ml}$. After $24 \mathrm{~h}, 20 \mathrm{ml}$ of MTT dye solution $(5 \mathrm{mg} / \mathrm{ml}$ in phosphate buffer $\mathrm{pH}=7.4)$ was added to each well. After $4 \mathrm{~h}$ of incubation at $37^{\circ} \mathrm{C}$, the medium was removed and formazan crystals were solubilised with $200 \mathrm{ml}$ of dimethylsulphoxide (DMSO) and the solution was vigorously mixed to dissolve the reacted dye. After $15 \mathrm{~min}$, the absorbance of each well was read on a microplate reader (DYNATECH MR7000 instruments) at $570 \mathrm{~nm}$. The spectrophotometer was calibrated to zero absorbance, using culture medium without cells. The relative cell viability (\%) related to control wells containing cell culture medium without nanoparticles was calculated by:

Cell viability $(\%)=$ Atest/Acontrol $\times 100$.

Where Atest is the absorbance of the test sample and Acontrol is the absorbance of control sample.

\subsection{Construction and identification of survivin SiRNA vector}

The pEGFP-U6-shRNA vector was presented as a gift by Professor Beate Brand-Saberi from Freiburg University, Germany. The vectors with anti-survivin SiRNA were constructed as follows: (a) the selected target sequence in the survivin gene (accession number: NM_001168) was from nucleotide 51 to 70 . The target

Scheme 1 Complexation between carboxyl SWCNTs and amine terminated PAMAM dendrimer. 
sequence was selected with the help of the Whitehead siRNA selection program (available at http://jura.wi.mit. edu/siRNAext; Bioinformatics and Research Computing at Whitehead Institute). A Blast search against the NCBI database revealed no significant homology of the targeted sequence to other genes (http://www.ncbi.nlm. nih.gov/BLAST). (b) as shown in Figure 1, as a survivin shRNA DNA template, one oligo sequence subsequently should include a sense sequence (5'-CACCG CATCT CTACA TTCAA GAATT CAAGA GATTC TTGAA TGTAG AGATG CTTTT TTG-3'), a loop sequence (5' TTCAAGAGA 3'), and an antisense sequence (5'-GATCC AAAAA AGCAT CTCTA CATTC AAGAA TCTCT TGAAT TCTTG AATGT AGAGA TGC -3'). For ligation to the vectors to occur, two enzyme restriction sequences for BamHI (at the 5' end) and Hind III (at the 3 'end) must locate at both ends. For later, convenient analysis of the DNA plasmid constructs, an EcoR I restriction sequence should be added before the Hind III sequence. (c) All oligonucleotides were synthesized by the Ambion Company and purified using polyacrylamide gel. They were dissolved in an annealing buffer $(10 \mathrm{mM}$ Tris-Cl (pH 8.0)/50 mM NaCl/1 mM EDTA) and annealed by heating to and stepwise cooling as follows: $95^{\circ} \mathrm{C}, 4 \mathrm{~min}$; $90^{\circ} \mathrm{C}, 4 \mathrm{~min} ; 85^{\circ} \mathrm{C}, 4 \mathrm{~min} ; 80^{\circ} \mathrm{C}, 4 \mathrm{~min} ; 75^{\circ} \mathrm{C}, 4 \mathrm{~min}$; $70^{\circ} \mathrm{C}, 4 \mathrm{~min} ; 65^{\circ} \mathrm{C}, 4 \mathrm{~min} ; 60^{\circ} \mathrm{C}, 4 \mathrm{~min} ; 55^{\circ} \mathrm{C}, 4 \mathrm{~min}$; $50^{\circ} \mathrm{C}, 4 \mathrm{~min} ; 45^{\circ} \mathrm{C}, 4 \mathrm{~min} ; 40^{\circ} \mathrm{C}, 4 \mathrm{~min} ; 35^{\circ} \mathrm{C}, 4 \mathrm{~min}$; $30^{\circ} \mathrm{C}, 4 \mathrm{~min} ; 25^{\circ} \mathrm{C}, 4 \mathrm{~min}$. The oligonucleotide-duplexes codings for survivin and scrambled shRNAs were ligated to BamH I- and Hind III-cleaved pEGFP-U6-shRNA vectors to generate a pEGFP-U6-shRNA-survivin vector respectively. After that, the insertion sequences were confirmed by sequencing, and the control vectors were constructed according to and the method described in reference [25].

\subsection{Dendrimer-coated SWCNTs mixing with pEGFP-U6-shRNA-survivin vector}

The $\mathrm{pH}$ of the solution was 7.4. A suspension of the dSWCNTs at a concentration of $0.025 \mathrm{mg} / \mathrm{ml}$ was mixed with $1 \mu \mathrm{M}$ pEGFP-U6-shRNA-survivin vectors for $2 \mathrm{~h}$ at room temperature prior to characterization or cellular incubation for intercellular uptake. The pEGFP-U6shRNA-survivin vectors were adsorbed nonspecifically onto the dendrimer-modified SWCNTs.

\subsection{Agarose gel electrophoresis}

$0.7 \%$ agarose gel electrophoresis was used to assess the formation of the dGN-pEGFP-U6-shRNA-survivin vector complex. The nanocomplexes were added to the wells of the ethidium-bromide agarose gel, the resulting gel was processed at $60 \mathrm{~V}$ for $20 \mathrm{~min}$ and then imaged using a Chemi-Doc system (Bio-Rad, Hercules, CA).

\subsection{Cell culture and observation by fluorescence microscopy and HR-TEM}

Human gastric cancer MG803 cells were cultured at $37^{\circ} \mathrm{C}$ in a humidified $5 \% \mathrm{CO}_{2}$ and $95 \%$ air atmosphere in DMEM containing $1 \times 10^{5} \mathrm{mU} / \mathrm{mL}$ of penicillin and 0.1 $\mathrm{mg} / \mathrm{mL}$ of streptomycin supplemented with $10 \%(\mathrm{v} / \mathrm{v})$ FCS. The MGC803 cells were collected, seeded into 12 well plates, and cultured for $24 \mathrm{~h}$ as the experiment cells. Next, $100 \mu \mathrm{L}$ dGN-pEGFP-U6-shRNA-survivin vector complexes were seeded into 6 well plates. Then, these vector complexes and the dendrimer-modified SWCNTs composites were seeded into other 6 well plates as the control cells. Finally, all the cells were cultured at $37^{\circ} \mathrm{C}$ for 24,48 and $72 \mathrm{~h}$. After culturing, these cells were observed by fluorescent microscopy. Then, the MGC803 cells were collected and embedded into paraffin and made into TEM specimens, which then were observed via HRTEM.

\section{9 Effects of dendrimer modified SWCNTs- pEGFP-U6-shRNA on MGC803 cells}

The MGC803 cells were cultured in a DMEM medium supplemented with $10 \%$ FBS and $1 \%$ penicillinstreptomycin at $37^{\circ} \mathrm{C}$ for $48 \mathrm{~h}$. The MGC 803 cells were collected and added into 24 well plates at the concentration of 5000 cells/well then, they were allowed to culture for $24 \mathrm{~h}$. Next, the $0.025 \mathrm{mg} / \mathrm{mL}$ dGN-pEGFPU6-shRNA vector nanocomplexes were added into the 24 well plates; at the same time, the control experiments with the dCNT-pEGFP-U6-shRNA vector or dCNT were set up, and continued to culture for 24,48 and $72 \mathrm{~h}$. MTT ( $5 \mathrm{mg} / \mathrm{mL}$ ) was prepared in PBS and $20 \mu \mathrm{L}$ was added to each well; the cells were incubated for $4 \mathrm{~h}$ at $37^{\circ} \mathrm{C}$, the medium was removed, $200 \mu \mathrm{L}$ dimethyl sulfoxide (DMSO) was added to each well, and the optical density (OD) of each well was determined to be $515 \mathrm{~nm}$, according to the microplate reader. The cell viability was calculated by the following formula [17]:

Cell viability $(\%)=\mathrm{OD}_{\text {the treated cells }} / \mathrm{OD}_{\text {the non-treated cells }}$

\subsection{Statistical analysis}

All data in this paper are presented as means result \pm S.D. Statistical differences were evaluated using the t-test and considered significant at $\mathrm{P}<0.01$. In addition, all data in this paper were obtained from three independent experiments with similar results.

\section{Results and Discussions}

\subsection{Characterization of dendrimer coated SWCNTs}

Size and morphology of SWCNTs and dendrimer coated SWCNTs were determined by TEM as shown in Figure 1. Figure 1a shows that the SWCNTs are $\sim 10 \mathrm{~nm}$ in diameter with length over $1 \mu \mathrm{m}$. The morphology of the SWCNTs after dendrimer coating was greatly changed as shown in Figure 1b. SWCNTs were shorten after HNO3 treatment from Figure 1b, the average length of CNTs is about $50 \mathrm{~nm}$. Importantly, a thick layer of PAMAM dendrimer coated onto SWCNTs surface can be clearly observed, indicating the formation of dendrimer coated SWCNTs nanohybrid. 

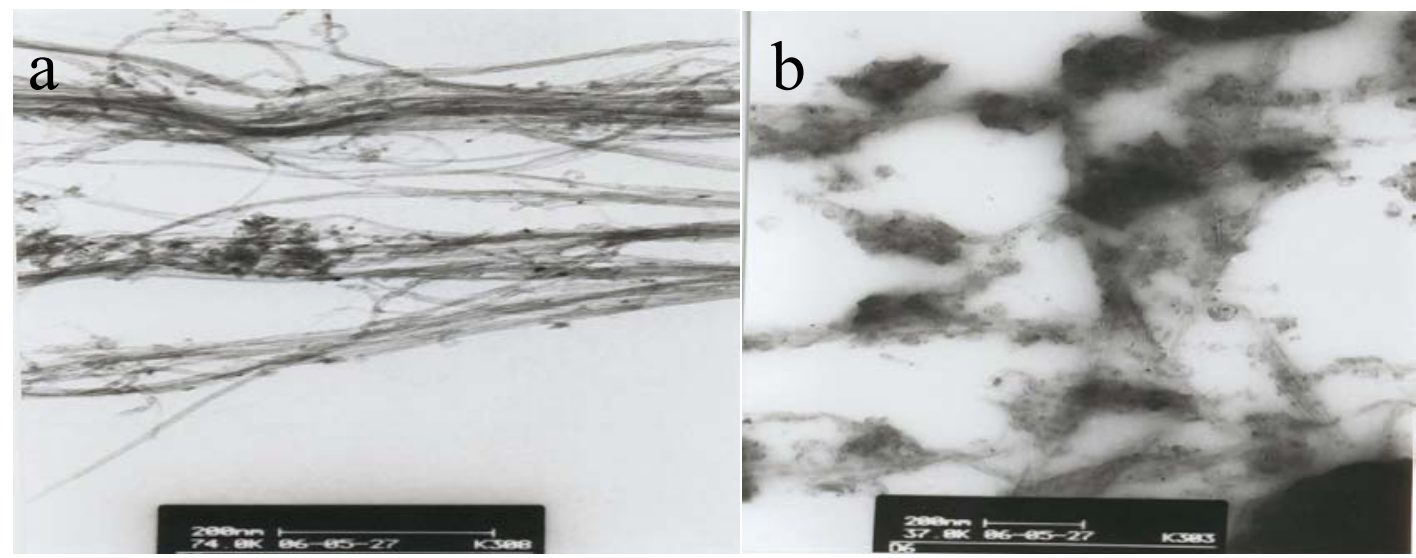

Fig. 1 TEM images of (a) SWCNTs and (b) G4.0 PAMAM dendrimer coated SWCNTs

\subsection{Effects of dendrimer-modified SWCNTs on MGC803 cells}

To examine the effect of dendrimer-coated SWCNTs on MGC803 cell growth and viability, MGC803 cells were incubated with dendrimer-coated SWCNTs complex for $24 \mathrm{~h}$, isolated by centrifugation and continued a $72 \mathrm{~h}$ incubation for MTT assay. Viable cells have the ability to reduce MTT from a yellow water-soluble dye to a dark blue insoluble formazan product. Formazan crystals were dissolved in DMSO and quantified by measuring the absorbance of the solution at $570 \mathrm{~nm}$, and the resultant value is related to the number of living cells. Figure 2 demonstrated a dose-dependent reduction in MTT absorbance in cells treated with dendrimer-coated SWCNTs (concentration range $0-1.0 \mathrm{mg} / \mathrm{ml}$ ) for $24 \mathrm{~h}$. As shown in Figure 2 (b) (e), Dendrimer coated SWCNTs showed no cytotoxic effects to cells and the cells remained more than $99 \%$ viable relative to control at concentration as high as $1.0 \mathrm{mg} / \mathrm{ml}$. No appreciable cell death was observed in the case of dendrimer coated SWCNTs. Theses results indicate that the PAMAM dendrimer coated SWCNTs exhibit little toxicity to MGC803 cells. The SWCNTs, however, was found to cause cell death when examined at $72 \mathrm{~h}$ after the $24 \mathrm{~h}$ incubation with

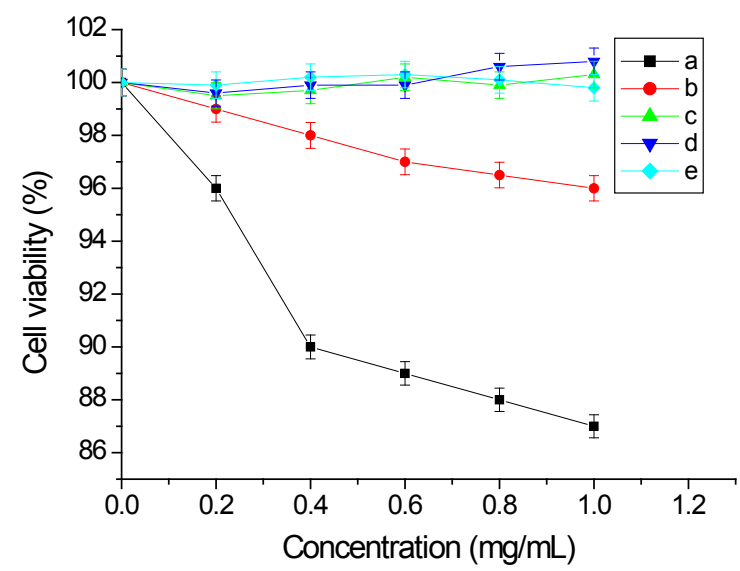

Fig. 2 Cytotoxicity profiles of SWCNTs and dendrimer coated SWCNTs, when incubated with MGC803 cells as determined by MTT assay. (a) SWCNTs, (b) G1.0 PAMAM dendrimer coated SWCNTs, (c) G2.0 PAMAM dendrimer coated SWCNTs, (d) G3.0 PAMAM dendrimer coated SWCNTs, (e) G4.0 PAMAM dendrimer coated SWCNTs.
MGC803 cells (Figure 2a). The degree of cell death was substantial as evidenced by the large amounts of cell debris observed. SWCNTs caused a significant reduction (96\% of control) in cell viability even at $0.2 \mathrm{mg} / \mathrm{mL}$ concentration tested, and induced further reductions at higher concentrations, reaching a plateau around $0.5 \mathrm{mg} /$ $\mathrm{ml}$, and that at the highest concentration tested $(1.0 \mathrm{mg} /$ $\mathrm{ml}$ ) it resulted in about $13 \%$ loss of cell viability.

\subsection{TEM observation of cellular uptake of dendrimer modified SWCNTs}

To investigate the cellular uptake of the dendrimer coated SWCNTs in vitro by TEM characterization. The TEM images showed that the dendrimer coated SWCNTs are internalized within the MGC 803 cells after $24 \mathrm{~h}$ incubation (Figure 3). Several electron lucent voids containing SWCNTs can be seen in the cytoplasm of the MGC803 cells forming the vacuoles. After $24 \mathrm{~h}$ incubation with MGC803 cells, the SWCNTs are internalized inside the cells, indicating PAMAM dendrimers can enhance the efficacy of SWCNTs entering into MGC803 cells.

\subsection{Construction and Identification of pCMV- EGFP-U6-shRNA vector}

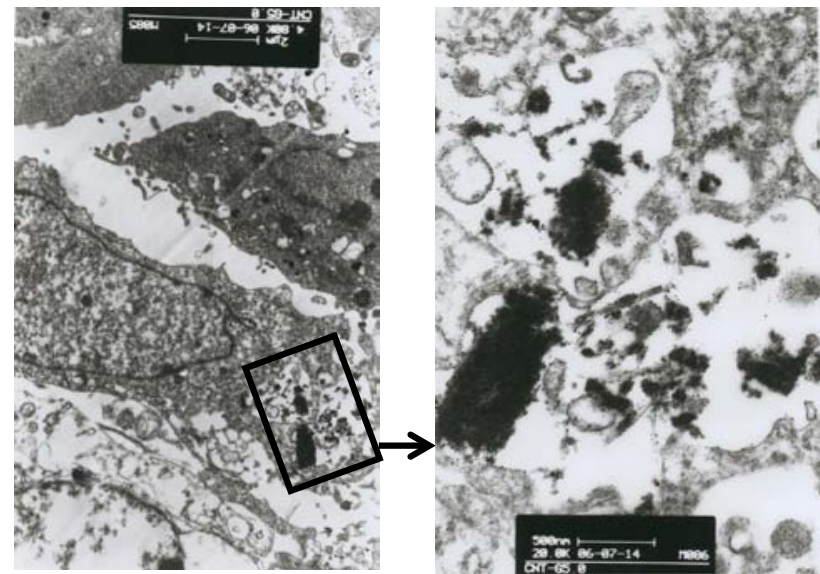

Fig. 3 TEM pictures of MGC803 cells incubated with G4.0 dendrimer coated SWCNTs showing SWCNTs internalization after $24 \mathrm{~h}$ incubation. 


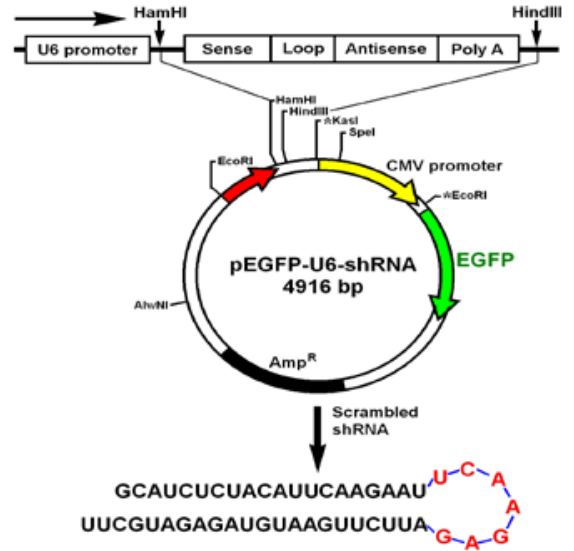

Fig. 4 Construction of pEGFP-U6-shRNA-survivin vector. Sequences of chemically synthesized anti-survivin, small hairpin RNAs (shRNAs) and their sense and antisense mRNA/cDNA target sequences.

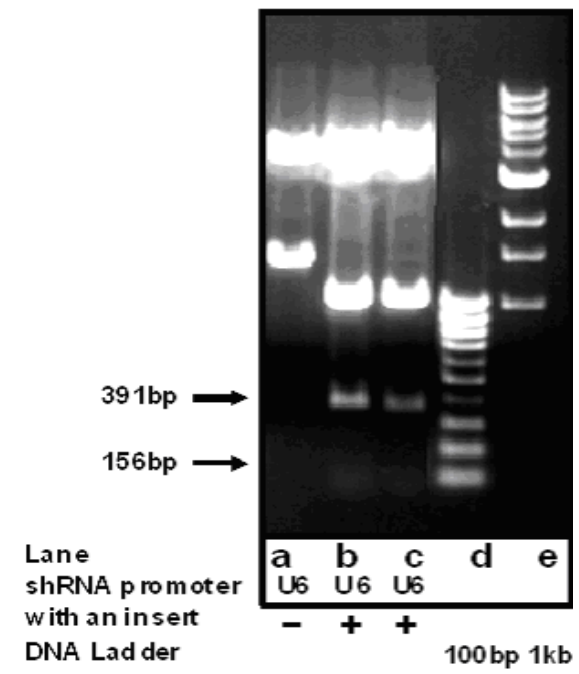

Fig. 5 Identification of pEGFP-U6-shRNA-anti-survivin siRNA vector cut with EcoR I by $0.7 \%$ agarose gel electrophoresis. a pEGFP-U6shRNA vector; $b$, c pEGFP-U6-shRNA-anti-survivin siRNA vector cut with EcoR I; d, e molecular markers.

The pCMV-EGFP-U6-shRNA vector was successfully constructed, as shown in Figure 4. UU indicates the deoxythydimidine dimmer as has a 3'-TT overhang.

Figure 5 shows the electrophoretic shift assay result of pCMV-EGFP-U6-anti-survivin plasmid and the control pCMV-EGFP-U6-shRNA plasmid digested with EcoR I. Compared with the control empty vector, the constructed pCMV-EGFP-U6-anti-survivin-shRNA plasmid has a
$156 \mathrm{bp}$ fragment, which is matched with the inserted survivin fragment, therefore, the pCMV-EGFP-U6shRNA-survivin plasmids (survivin-siRNA vector) were successfully constructed.

We also finished the electrophoretic shift assay result of survivin-siRNA vector in the absence and presence of dSWCNTs, which showed that the amine-terminated dSWCNTs composites could bind with survivin-siRNA vector and formed stable dSWCNT-survivin-siRNA composites. Zeta potential analysis showed that, after G4.0 dendrimer modified SWCNTs, zeta potential reached $+30 \mathrm{mV}$ at $\mathrm{pH} 7.0$, which is due to the increasing positive charges of $-\mathrm{NH}^{3+}$ on the surface of SWCNTs. The dSWCNTs with positive charge can bind with survivinsiRNA vector with negative charge via electrostatic attraction. G4.0 dSWCNTs absorbed the maximal amount of survivin-siRNA vectors. Positively charged survivinsiRNA-dSWCNTs would be easily attached to negatively charged cell membrane to improve the endocytosis. More positive charges on the surface of survivin-siRNAdSWCNTs make higher gene delivery efficiency.

\subsection{Effects of survivin-siRNA-dSWCNTs on MGC80 3 cells}

As shown in Figure 6A, G4.0 dSWCNTs can inhibit the growth of MGC803 cells with the inhibition rate of $8 \%$, showing that the dSWCNTs are very low toxic to MGC803 cancer cells. Under identical condition, the survivin-siRNA-dSWCNTs composites have the inhibition rate of $65 \%$, the control empty vector$\mathrm{dSWCNTs}$ composites only have the inhibition rate of $7 \%$, there exists statistical difference between two groups $(\mathrm{P}<0.01)$, showing that inserted survivin fragment was very effective. As shown in Figure 6C, G4 dSWCNTssurvivin-siRNA composites inhibited the growth of MGC803 cells in dose-dependent means. As shown in Figure 6D, the MGC803 cells exhibited strong green color, showing the positive expression of survivin-siRNA vector in MGC803 cells, and also indirectly suggesting that dendrimer-modified SWCNTs did not affect the survivin-siRNA vector expression in MGC803 cells. In summary, our results show that dendrimer coated SWCNTs may be one kind of good siRNA delivery system, which can be used for intracellular siRNA imaging and therapy.
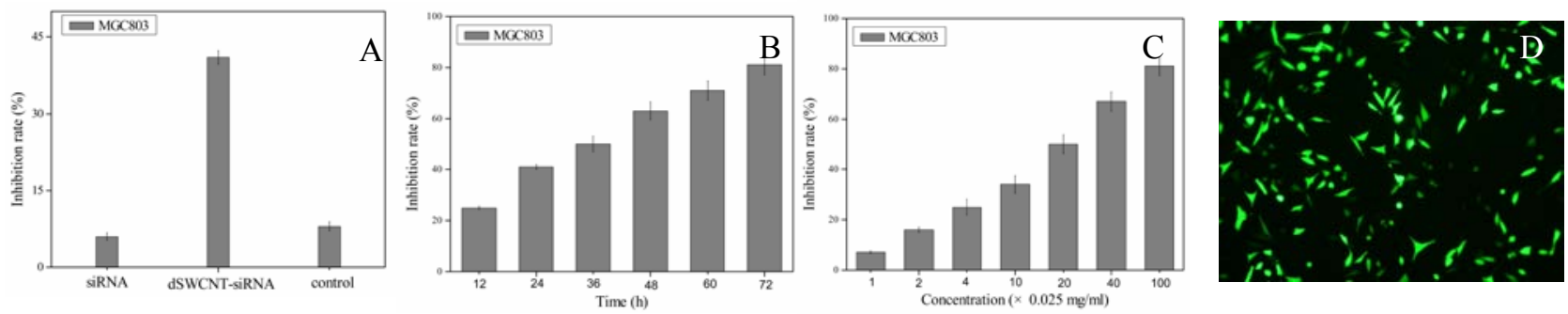

Fig. 6 Growth inhibition curves and fluorescent microscope observation of MGC803 cells. (A) dSWCNTs, siRNA-dSWCNTs and control at 24 h, (B) survivin siRNA-dSWCNTs composites at different time, (C) survivin-siRNA-dSWCNTs composites at different concentration dSWCNTs $+2 \mu \mathrm{M}$ siRNA vector, control: $0.025 \mathrm{mg} / \mathrm{mL}$ dSWCNTs $+2 \mu \mathrm{M}$ dSWCNTs-pCMV-EGFP-U6-shRNA vectors .(D) Fluorescent microscope observation of MGC803 cells incubated with dSWCNTs-pCMV-EGFP-U6-shRNA vectors. $(\times 20)$ 


\section{Conclusions}

In conclusion, dendrimer coated SWCNTs were successfully prepared, the colloidal solution of dendrimer coated SWCNTs showed high water-soluble, stability. The dendrimer coated SWCNTs were low cytotoxicity, which can bind with survivin siRNA vector via electrostatic interaction, resultant survivn siRNA SWCNTs can enter into MGC 803 cells high efficiently, the survivin siRNA vector can be released out from the nanocomposites of survivin siRNA vector-dSWCNTs, and inhibited the growth of tumor cells, the EGFP exhibited strong expression in MGC803 cells, the dendrimer modified SWCNTs may be one kind of delivery system for siRNA, and own great potential in applications such as gene or siRNA delivery, and intracellular imaging.

\section{Acknowledgements}

This work is supported by the National Key Basic Research Program (973 Project) (No. 2011CB933100), National Natural Scientific Fund (No.81225010, 31100717), 863 project of China (2012AA022703), Shanghai Science and Technology Fund (No.13NM1401500), Shanghai Jiao Tong University Innovation Fund for Postgraduates (No. AE340011).

\section{References}

1 Pan BF, Cui DX, Ozkan CS, Ozkan M, Xu P, Huang T, Liu FT, Chen H, Li Q, He R, Gao F. Effects of carbon nanotubes on photoluminescence properties of quantum dots. J. Phys. Chem. C 2008; 112: 939-944

2 Cui DX, Pan BF, Zhang $\mathrm{H}$, Gao F, Wu R, Wang JP, He R, Asahi T. Self-Assembly of Quantum Dots and Carbon Nanotubes for Ultrasensitive DNA and Antigen Detection. Anal. Chem. 2008; 80: 7996-8001.

3 Xu P, Cui DX, Pan BF, Gao F, He R, Li Q, Huang T, Bao CC, Yang H. A facile strategy for covalent binding of nanoparticles onto carbon nanotubes. Appli. Surf. Sci. 2008; 254: 5236-5240.

4 Pan BF, Cui D.X., Xu P., Chen H., Liu FT., Li Q., et al. Design of dendrimer modified carbon nanotubes for gene delivery. Chinese J. Cancer Rese. 2007; 19: 1-6.

5 Münzer AM., Michael ZP., Star A. Carbon Nanotubes for the Label-Free Detection of Biomarkers. ACS Nano, 2013; in press.

6 Hong H., Chen F., Cai W. Pharmacokinetic issues of imaging with nanoparticles: focusing on carbon nanotubes and quantum dots. Mol. Imaging Biol. 2013;15(5):507-520.

7 Cui DX, Ozkan CS., Tian FR., Kong Y. Delivery of Gold Nanoparticles Inside Carbon Nanotubes by Oligonucleotides. Nano Biomed. Eng. 2011, 3(4), 243-248.

8 Gao HJ., Kong Y., Cui D., Ozkan CS. Spontaneous insertion of DNA oligonucleotides into carbon nanotubes. Nano Lett. 2003; 3:471473.

9 Cui DX, Tian FR, Coyer SR, Wang JC, Pan BF, Gao F, He R, Zhang YF. Effects of antisense-myc-conjugated single-walled carbon nanotubed on HL-60 cells. J. Nanosci. Nanotechnol. 2007;7: 16391646 .
10 Wang YK., Lin Q., Wu KJ., Zhu MJ., Lu YS., Chen J., Huang S., Cheng XH., Weng ZY.. Experimental study of bio-security of functionalized single-walled and multi-walled carbon nanotubes. Nano Biomed.Eng. 2011, 3(4), 249-255.

11 Cui DX, Zhang H., Wang Z. , Feng LL., Ruan J., Toru A., Tetsuya O. Dendrimer-functionalized multi-walled carbon nanotubes exhibit dual-phase regulation to exposed murine embryonic stem cells. Nano Biomed. Eng. 2011, 3(4), 227-231.

12 Tian FR, Cui DX, Schwarz H, Estrada GG, Kobayashi H Cytotoxicity of single-wall carbon nanotubes on human fibroblasts. Toxicol. in vitro 2006; 20: 1202-1212.

13 Cui DX. Advances and prospects on biomolecules functionalized carbon nanotubes. J. Nanosci. Nanotechnol. 2007;7: 1298-1314.

14 Yuan HG, Hu SL, Huang P, Song H, Wang K, Ruan J, He R, Cui DX. Single Walled Carbon Nanotubes exhibit dual-phase regulation to exposed arabidopsis mesophyll cells. Nanoscale Res. Lett. 2010; 6: 322.

15 Huang P., Lin J., Yang DP., Zhang CL., Li ZM., Cui D. Photosensitizer-loaded dendrimer-modified multi-walled carbon nanotubes for photodynamic therapy. J. Controlled Release 2011; 152(S): E33-E34.

16 Tian Z., Shi YF., Yin M., Shen HB., Jia NQ. Functionalized Multiwalled Carbon Nanotubes-anticancer Drug Carriers: Synthesis, Target-ing Ability and Antitumor activity. Nano Biomed. Eng. 2011, 3(3), 157-162

17 Pan BF, Cui DX, Gao F, He R. Growth of multi-amine terminated poly(amidoamine) dendrimerson the surface of carbon nanotubes. Nanotechnology, 2006; 17: 2483-2489.

18 Pan BF, Cui DX, He R, Gao F, Zhang YF. Covalent attachment of quantum dot on carbon nanotubes. Chem. Phys. Lett. 2006; 417: 419-424.

19 Huang P., Zhang CL., Xu C., Bao L., Li ZM. Preparation and characterization of near infrared region absorption enhancer carbon nanotubes hybridmaterials. Nano Biomed. Eng. 2010, 2(4), $225-$ 230.

20 Cui DX, Tian FR., Ozkan CS., Wang M., Gao HJ. Effects of single walled carbon nnaotubes on human HEK293 cells. Toxicology Lett. 2005; 155:73-85.

21 Pan BF, Cui DX, Xu P, Ozkan CS, Gao F, Ozkan M, Huang T, Chu $\mathrm{BF}$, Li Q, He R, Hu GH.Synthesis and characterization of polyamidoamine dendrimer-coated multi-walled carbon nanotubes and their application in gene delivery systems. Nanotechnology 2009; 20:125101.

22 Brummelkamp TR, Bernards R, Agami R (2002) A system for stable expression of short interfering RNAs in mammalian cells. Science 296: 550-553.

23 Caplen NJ (2004) Gene therapy progress and prospects. Downregulating gene expression: The impact of RNA interference. Gene Ther: 11, 1241-8.

24 Chiu YL, Rana TM (2002) RNAi in human cells: Basic structural and functional features of small interfering RNA. Mol. Cell 10, 549-61.

25 Dai F, Yusuf F, Farjah GH, Brand-Saberi B. RNAi-induced targeted silencing of developmental control genes during chicken embryogenesis. Dev Biol 285:80-90.

26 Elbashir SM, Lendeckel W, Tuschl T (2001) RNA interference is mediated by 21- and 22-nucleotide RNAs. Genes Dev 15:188-200.

27 Elbashir SM, Harborth J, Lendeckel W, Yalcin A, Weber K, Tuschl T (2001) Duplexes of 21-nucleotide RNAs mediate RNA interference in cultured mammalian cells. Nature 411: 494-498.

28 Filipowicz W. RNAi: the nuts and bolts of the RISC machine. Cell 2005 122:17-20.

Copyright:(c) 2013 C. Wang et al. This is an open-access article distributed under the terms of the Creative Commons Attribution License, which permits unrestricted use, distribution, and reproduction in any medium, provided the original author and source are credited. 